\title{
Online Appendix: Consumers' Response to State Energy Efficient Appliance Rebate Programs
}

\author{
Sébastien Houde, Joseph E. Aldy*
}

January 10, 2017

Our empirical strategy exploits variations across time and regions to isolate the effects of rebates. The time fixed effects are then crucial for controlling the effects of the retailer's pricing and advertising strategies. Although the retailer employed a national pricing strategy, one concern is that store managers in some states systematically deviated from the national strategy such that promotions and marketing efforts are correlated with the implementation of the rebate programs.

The national pricing strategy is illustrated in Figures A.4 and A.5 that show the median prices of the most popular refrigerator models for two major brands. ${ }^{1}$ Each panel plots the weekly variation in price for a specific model of a specific brand. For each brand, we show the weekly variation for the nine most popular models offered by this brand. We use the sales rank during the period 20082012 as our measure of popularity. The red line corresponds to the median change in price relative to the average price over the lifetime of the product, where the median is taken across zip codes. That is, we computed week-zip code-specific changes in price for each model and then plotted the median of the weekly changes for a specific model. The grey band identifies the $25^{\text {th }}$ and $75^{\text {th }}$ percentile of these weekly changes in price. By presenting various quantiles of the distribution of weekly changes, we show that the local store managers comply with the national pricing policy; for the vast majority of weeks the $25^{\text {th }}$ and $75^{\text {th }}$ percentiles perfectly coincide with the median. Discrepancies occur

\footnotetext{
*Houde: Department of Agricultural and Resource Economics, University of Maryland; 2222B Symons Hall. College Park, MD 20742 (e-mail: shoude@umd.edu); Aldy: John F. Kennedy School of Government, Harvard University; Resources for the Future; National Bureau of Economic Research; Center for Strategic and International Studies; Harvard Kennedy School, 79 JFK Street, Mailbox 57, Cambridge, MA 02138 (e-mail: Joseph_Aldy@hks.harvard.edu). We first would like to thank Hasan Nazar, who worked on this project during his studies and as a research assistant at Harvard. We thank Carlos Paez for his excellent research assistance as well. We thank Chris Cloutier, Brandon Hurlbut, Lani MacRae, Susanne Rivera, and Toby Swope for assistance with the DOE SEEARP data. We would also like to thank Kenneth Gillingham, Lucas Davis, and two referees, in addition to numerous seminar participants at Harvard, the Stanford Institute of Theoretical Economics, and the AERE summer conference in Banff for feedback on earlier drafts of this paper.

${ }^{1}$ Brand names are anonymized to keep the confidentially of the data. Similar patterns are found for other brands, but not shown here.
} 
mostly at the time of large price changes, which suggests some stickiness of in-store prices surrounding those events.

Given that store managers comply with the national pricing strategy, we find that the week-year fixed effects do well in controlling for the variation in prices. Figure A.6 compares the ES market shares with normalized market shares, which are the residuals of a regression of market shares on week-year and state fixed effects. If the week-year fixed effects were to capture most of the temporal variation that is attributable to prices, we should expect that the normalized market shares in states that did not offer rebates for a given appliance category would be tightly concentrated around zero. This is exactly what we observe.

Below, we investigate alternative specifications that further validate the difference-in-differences strategy. First, we use the micro-data directly and control for demographics. Adding demographics allows us to account for changes in the composition of consumers going to the retailer's stores caused by the recession, which program administrators may have forecasted. For instance, program administrators in states where low-income households were hard hit by the recession may have decided to offer more generous rebates to attract these consumers to appliance stores. By controlling for demographics, income for instance, we are estimating the effect of rebates holding household composition fixed. To implement this estimator, we add to Equation ?? a vector of household-specific demographics that includes income, education, age of the head of the household, family size, political orientation, type of housing, and a home ownership dummy. Table A.4 shows the results where the dependent variable is the log of the expected energy use of the appliance purchased by each household. Overall, the results are similar to the main results relying on week-state averages. This suggests that changes in household composition are not an important source of endogeneity.

Second, Table A.5 presents results where we include state-specific pre-announcement linear time trends in addition of the state-year fixed effects. This has little impact on the estimates. In general, we find little evidence that time-varying unobservables at the state level are an important concern in this context. As shown on Table A.6, using state fixed effects, instead of state-year fixed effects, leads to similar results.

In the last specification test that we present (Table A.7), we exclude five states from the analysis: Florida, Iowa, Illinois, North Carolina, and Oregon. Iowa was excluded because the DOE data revealed that several claims differed drastically from the program guidelines. We found 375 instances of rebate claims covering $90 \%$ of the appliance cost and exceeding $\$ 1,000$. Other states were excluded because they offered ad valorem rebates. For these states, using the average rebate amount then leads to measurement error. Performing the estimation without these five states leads to qualitatively similar results for all three appliance categories. 


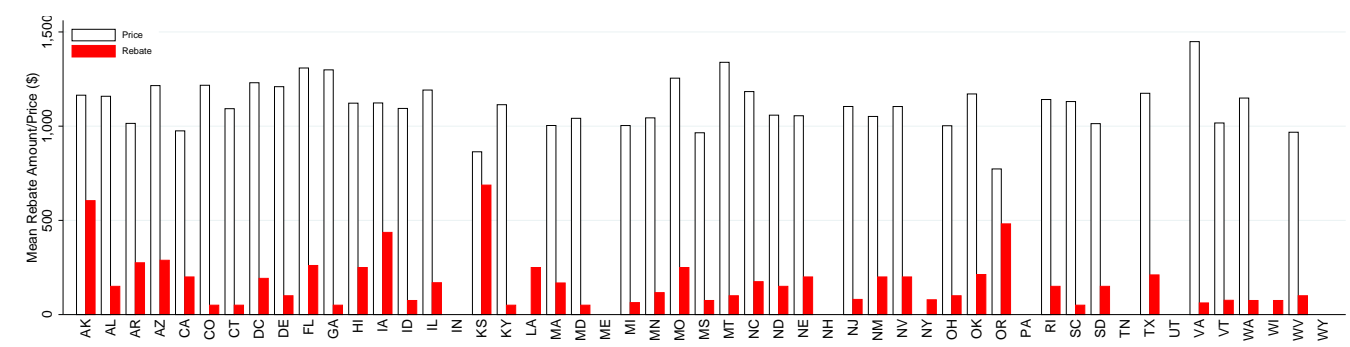

(a) Refrigerators

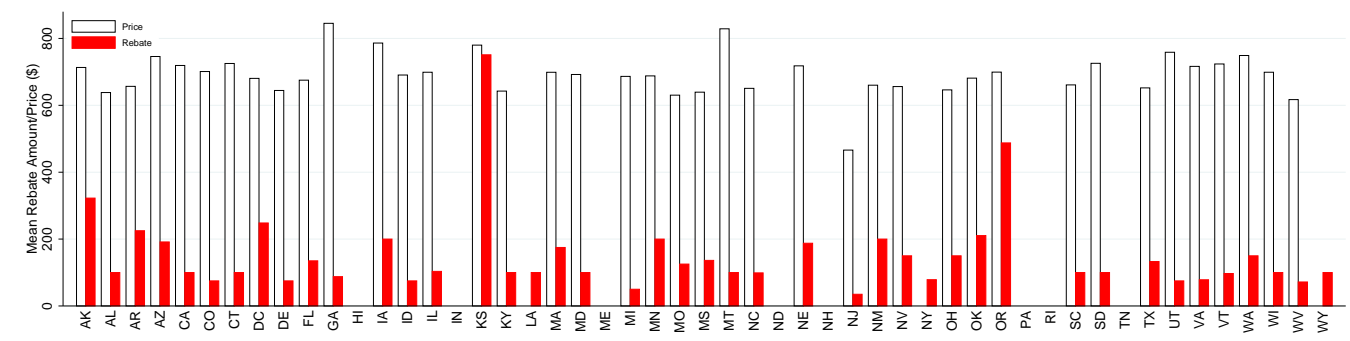

(b) Clothes Washers

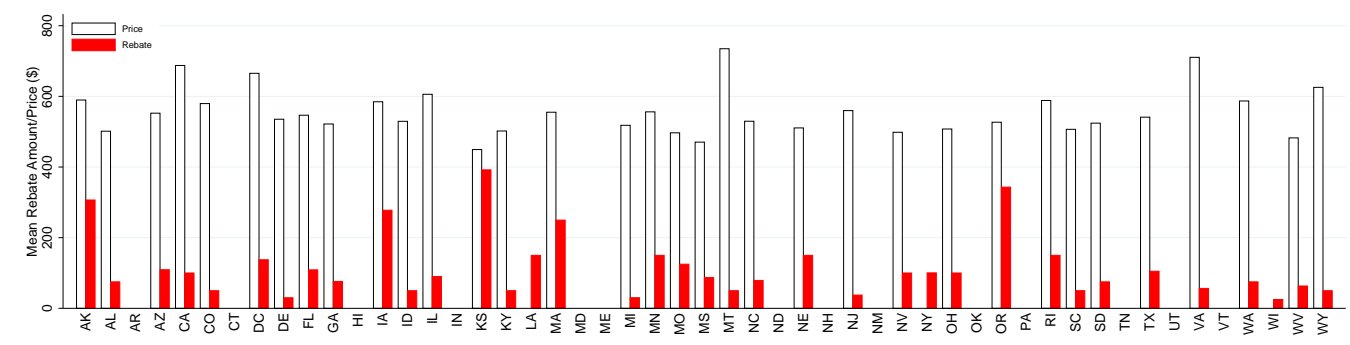

(c) Dishwashers

Figure A.1: Average Price vs. Rebate Amount

Each panel shows the average price of the appliance purchased (in white) and the average rebate amount claimed (in red). States with no average price but a positive rebate amount are states where program managers did not collect price information. States where both price and rebate information are missing did not offer rebates for this particular appliance. 


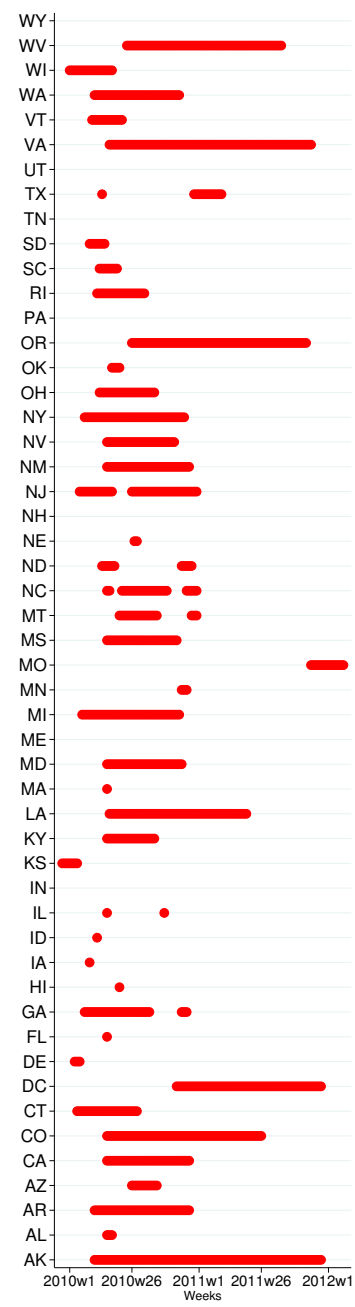

(a) Refrigerators

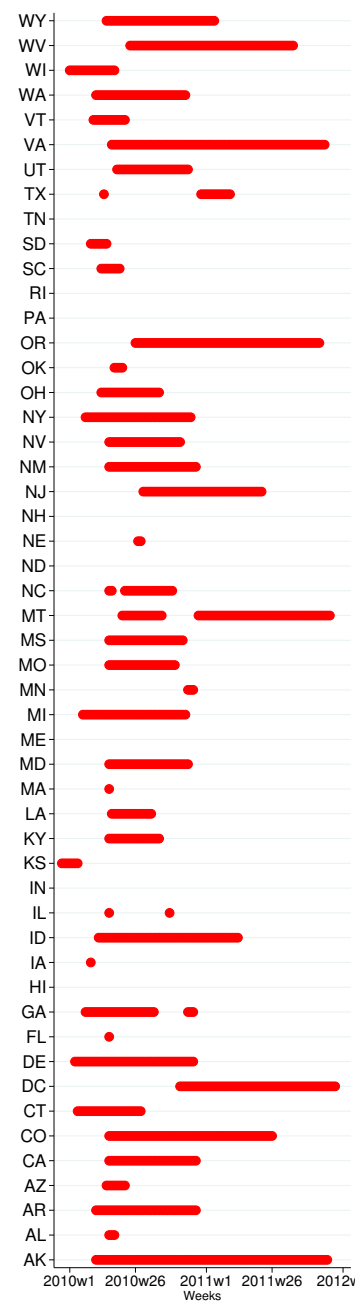

(b) Clothes Washers

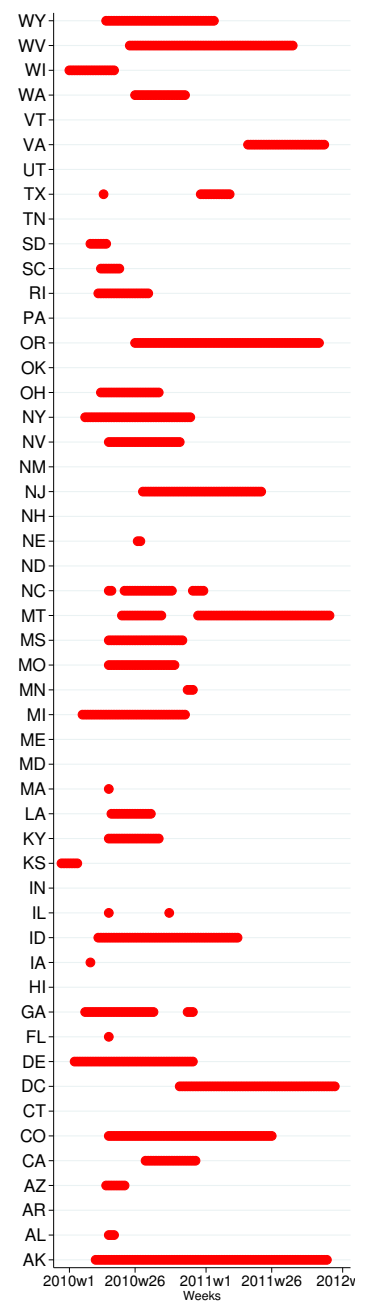

(c) Dishwashers

Figure A.2: Timing of Active Rebate Programs

Each panel identifies the weeks that a state rebate program was active for specific appliance category. 

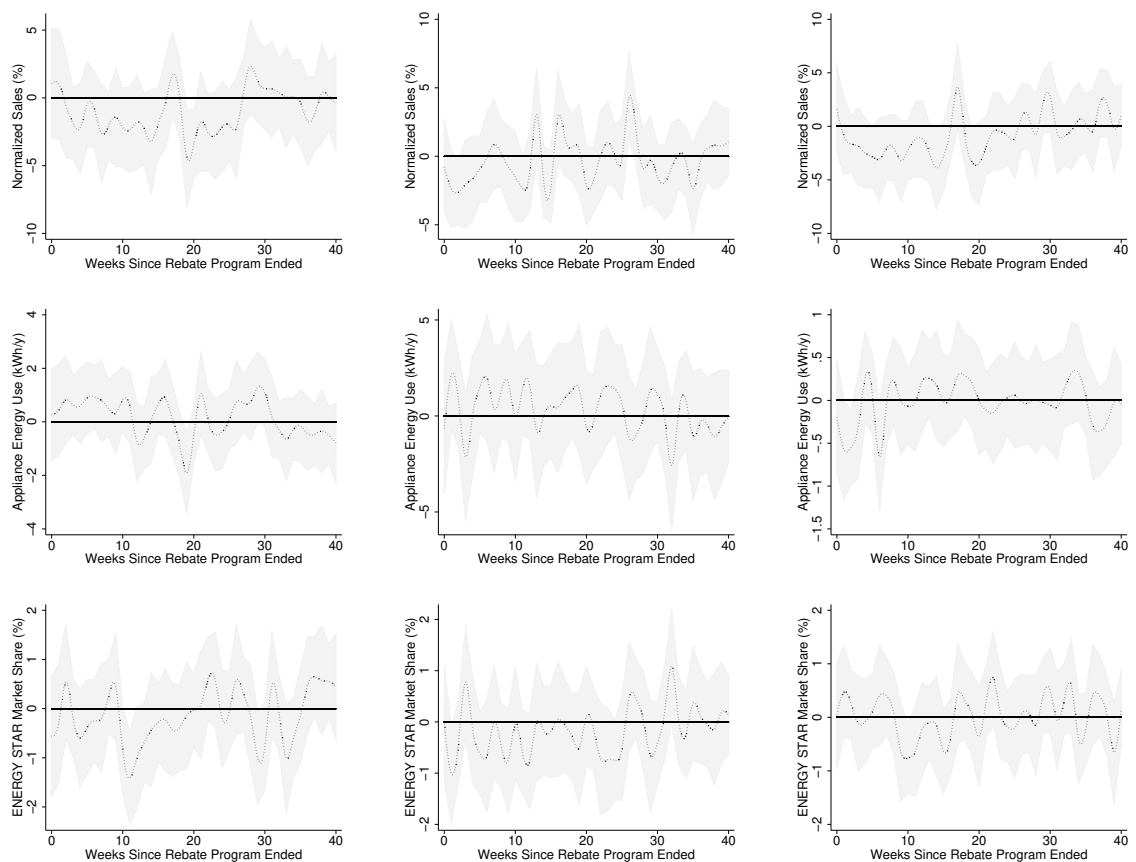

(a) Refrigerators

(b) Clothes Washers

(c) Dishwashers

Figure A.3: Sales, Energy Efficiency, and ENERGY STAR Market Share: PostRebate Period

The figure shows normalized sales, expected appliance energy use $(\mathrm{kWh} / \mathrm{y})$, and ES market share. All three outcome variables are normalized using a regression that removes week-ofsample and state-year fixed effects. The figure presents a fitted spline and the $95 \%$ confidence interval. The $\mathrm{X}$-axis corresponds to the number of weeks after a rebate program ended. 

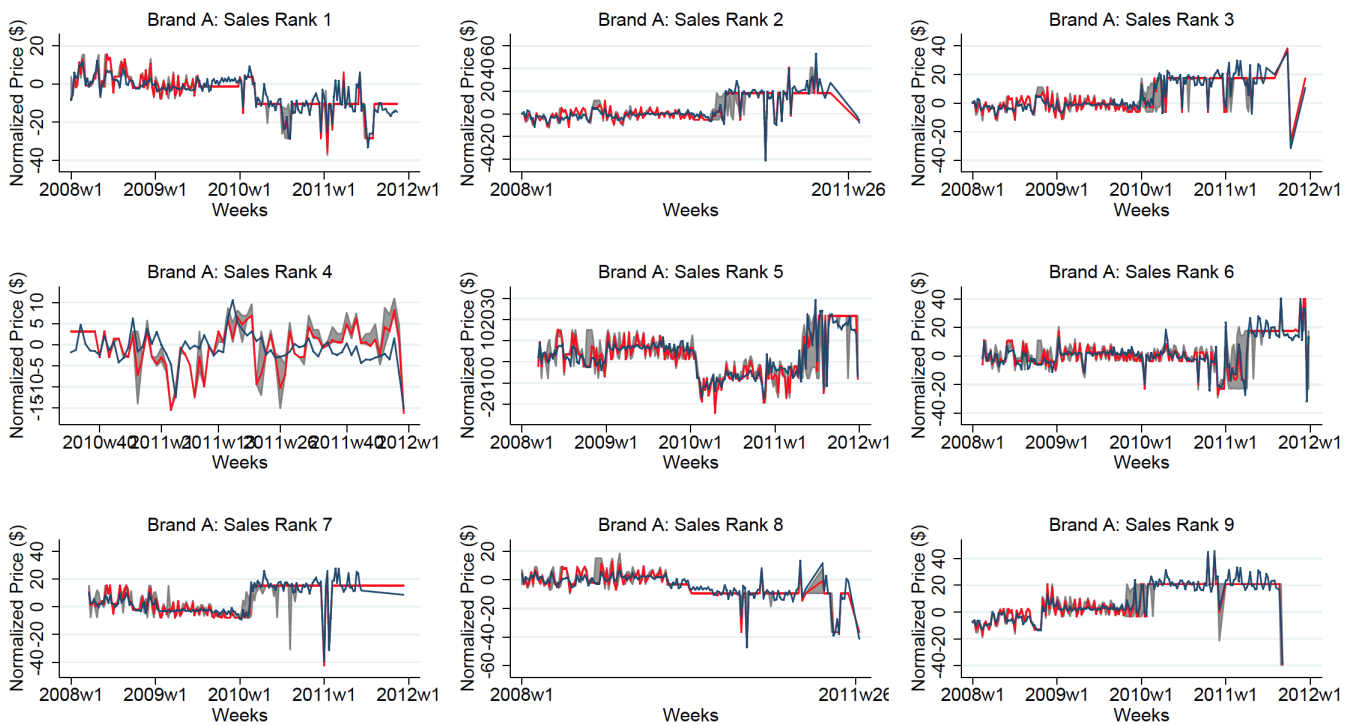

Figure A.4: Temporal and Cross Store Variation in Promotional Price, Nine Refrigerators of Brand A

Notes: The red line shows the normalized prices of the nine most popular refrigerator models offered by Brand A. The gray shaded are corresponds to the $25^{t h}$ and $75^{\text {th }}$ percentile of the normalized price distribution. The blue line is the median price after controlling for brandweek-of-sample fixed effects. 

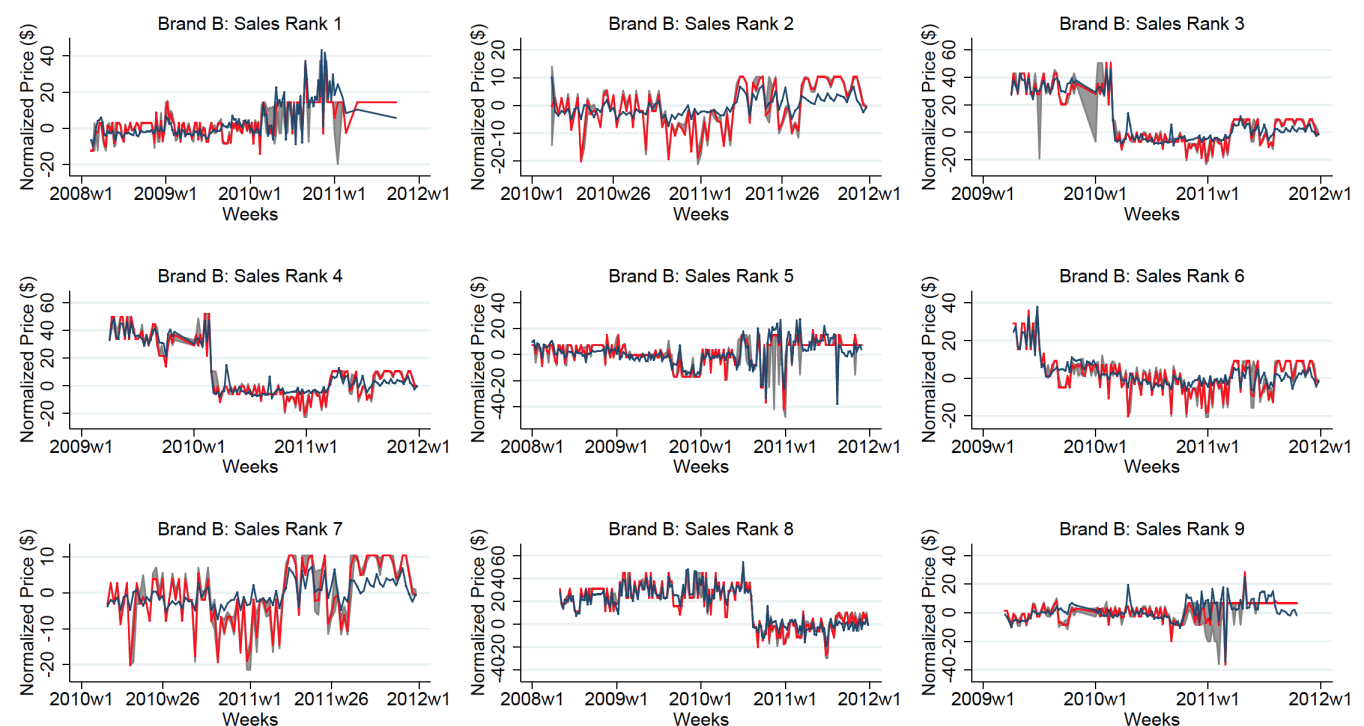

Figure A.5: Temporal and Cross Store Variation in Promotional Price, Nine Refrigerators of Brand B

Notes: The red line shows the normalized prices of the nine most popular refrigerator models offered by Brand B. The gray shaded are corresponds to the $25^{\text {th }}$ and $75^{\text {th }}$ percentile of the normalized price distribution. The blue line is the median price after controlling for brandweek-of-sample fixed effects. 


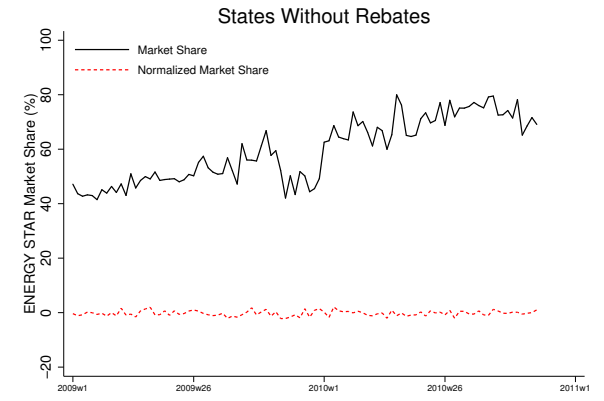

(a) Refrigerators

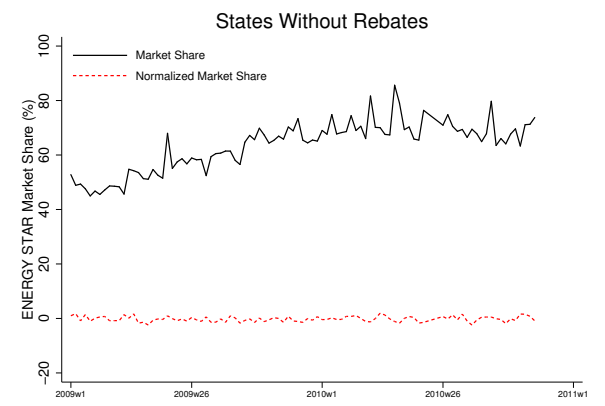

(b) Clothes Washers

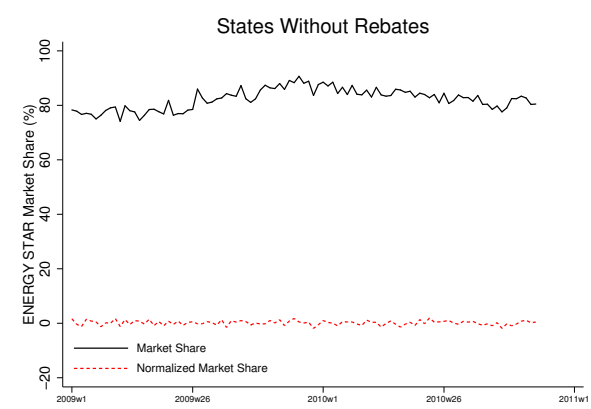

(c) Dishwashers

Figure A.6: ES Market Shares vs. Normalized Market Shares, States Without Rebates

Each panel shows the weekly ES market share for all states that did not offer rebates and the corresponding normalized market shares. Normalized market shares are the residuals of a regression of market shares on state and week-year fixed effects. The figure shows that, for states without rebates, the fixed effects capture most of the variations in market shares. 
Table A.1: External Validity

\begin{tabular}{|c|c|c|c|}
\hline & Retailer & Other Retailers & t-statistics \\
\hline \multicolumn{4}{|c|}{ Refrigerators } \\
\hline Price & 1154 & 1083 & 25.17 \\
\hline Rebate & 180 & 135 & 98.84 \\
\hline $\mathrm{kWh}$ & 480 & 456 & 60.92 \\
\hline Size & 22 & 20 & 14.46 \\
\hline \multicolumn{4}{|c|}{ Clothes Washers } \\
\hline Price & 699 & 674 & 24.41 \\
\hline Rebate & 114 & 113 & 4.66 \\
\hline $\mathrm{kWh}$ & 160 & 175 & -48.92 \\
\hline Size & 4 & 4 & 0.63 \\
\hline \multicolumn{4}{|c|}{ Dishwashers } \\
\hline Price & 554 & 543 & 7.64 \\
\hline Rebate & 116 & 85 & 86.97 \\
\hline $\mathrm{kWh}$ & 160 & 174 & -1.54 \\
\hline Size & 4 & 4 & 0.05 \\
\hline \multicolumn{4}{|c|}{$\begin{array}{l}\text { Notes: Using the DOE data alone, this table com- } \\
\text { pares the average price, rebate amount, kWh pur- } \\
\text { chased, and size of the appliances purchased at our } \\
\text { retailer (retailer from which we collected transac- } \\
\text { tion level data) versus all other retailers. Note } \\
\text { that some states did not record the retailer where } \\
\text { the purchase was made. }\end{array}$} \\
\hline
\end{tabular}


Table A.2: External Validity: Consumers

\begin{tabular}{|c|c|c|}
\hline & Retailer & Others \\
\hline Median Household Income & $\begin{array}{c}68089 \\
(26118.0)\end{array}$ & $\begin{array}{c}66701 \\
(25308.2)\end{array}$ \\
\hline Median Age in Years & $\begin{array}{c}39.2 \\
(6.359)\end{array}$ & $\begin{array}{c}39.4 \\
(6.249)\end{array}$ \\
\hline Average Household Size & $\begin{array}{c}2.7 \\
(0.444)\end{array}$ & $\begin{array}{c}2.7 \\
(0.420)\end{array}$ \\
\hline Female Population Share & $\begin{array}{c}50.9 \\
(2.390)\end{array}$ & $\begin{array}{c}51.0 \\
(2.390)\end{array}$ \\
\hline White Population Share & $\begin{array}{c}75.3 \\
(19.16)\end{array}$ & $\begin{array}{c}77.0 \\
(19.22)\end{array}$ \\
\hline Black Population Share & $\begin{array}{c}7.8 \\
(11.77)\end{array}$ & $\begin{array}{c}7.7 \\
(11.98)\end{array}$ \\
\hline Hispanic Population Share & $\begin{array}{c}18.6 \\
(19.03)\end{array}$ & $\begin{array}{c}14.9 \\
(16.83)\end{array}$ \\
\hline Homeowner Share & $\begin{array}{c}67.4 \\
(15.38)\end{array}$ & $\begin{array}{c}68.0 \\
(16.00)\end{array}$ \\
\hline Below Poverty Line Share & $\begin{array}{c}11.9 \\
(7.497)\end{array}$ & $\begin{array}{c}12.0 \\
(7.634)\end{array}$ \\
\hline High School Graduate Share & $\begin{array}{c}29.0 \\
(9.641)\end{array}$ & $\begin{array}{c}29.1 \\
(9.806)\end{array}$ \\
\hline College Graduate or Above & $\begin{array}{c}11.6 \\
(8.899)\end{array}$ & $\begin{array}{c}12.1 \\
(9.106)\end{array}$ \\
\hline Observations & 135678 & 450581 \\
\hline
\end{tabular}




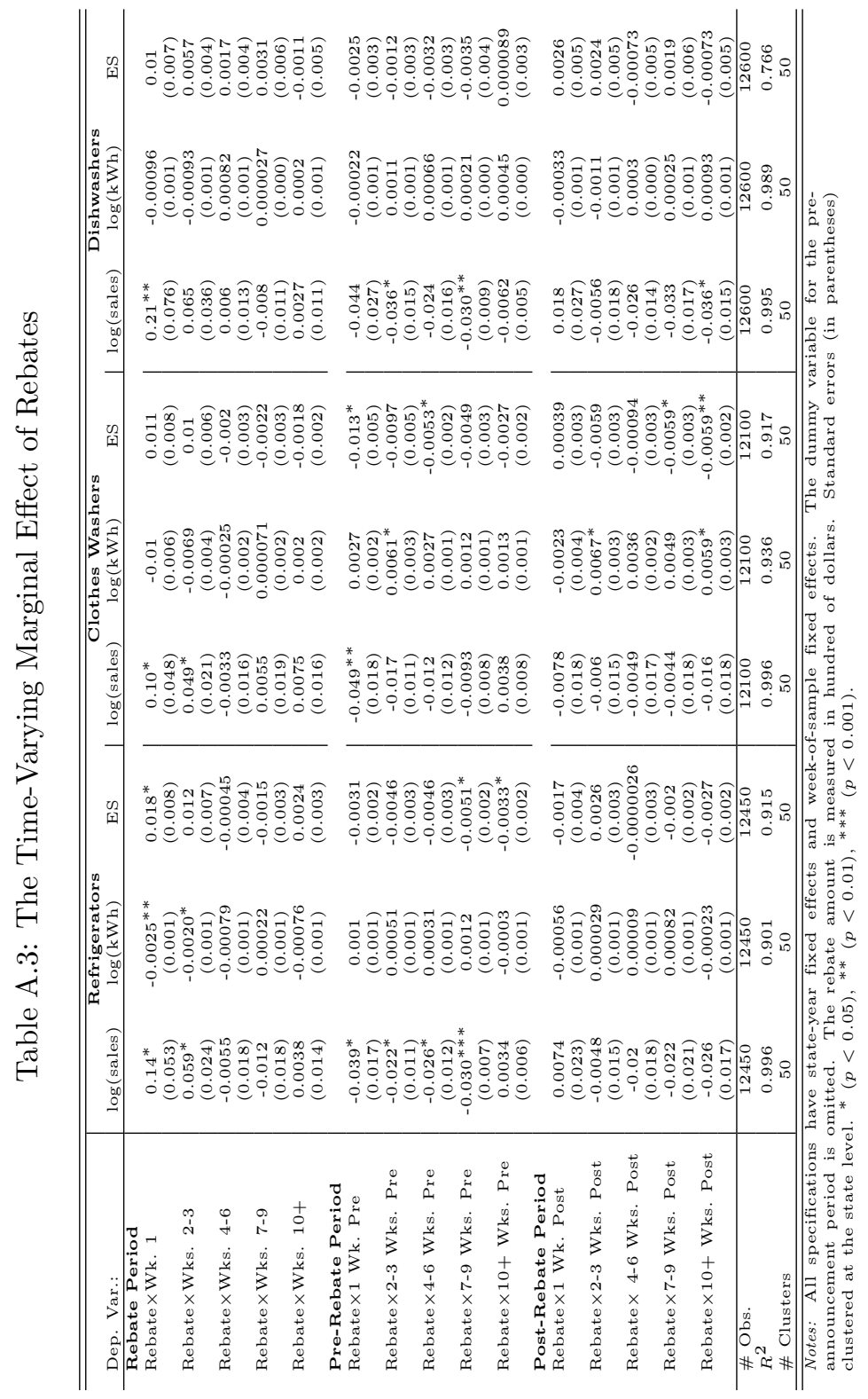




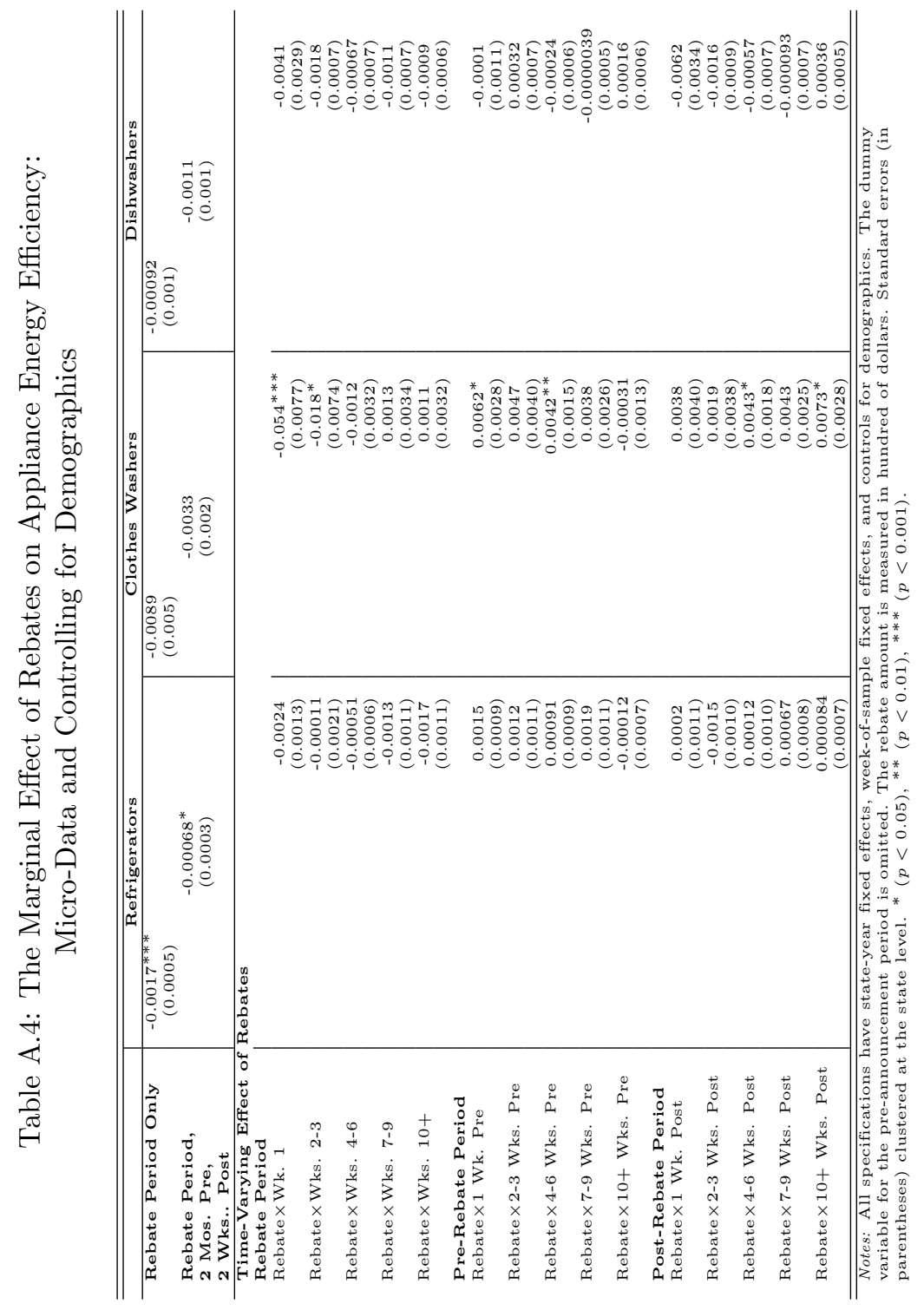




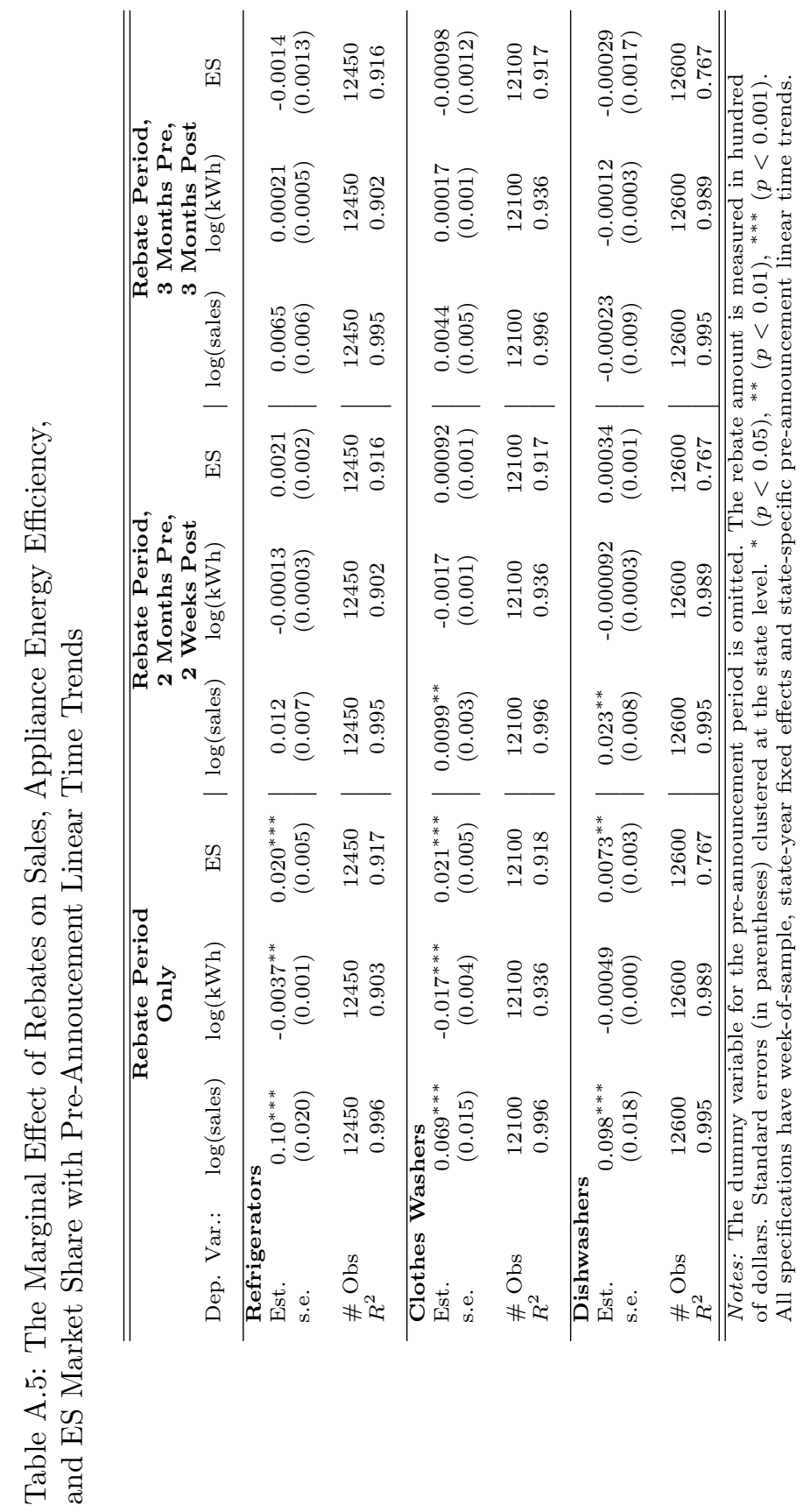




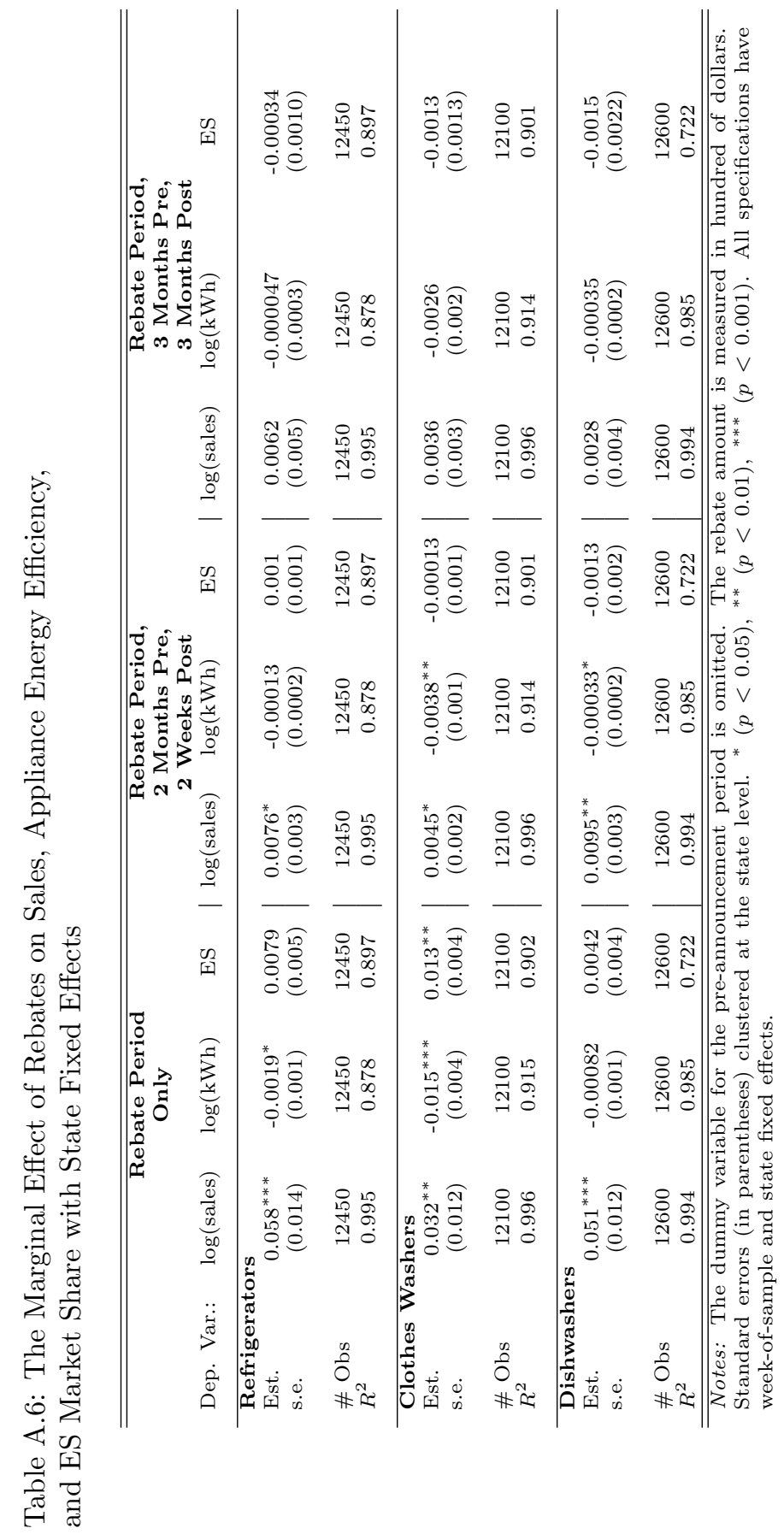




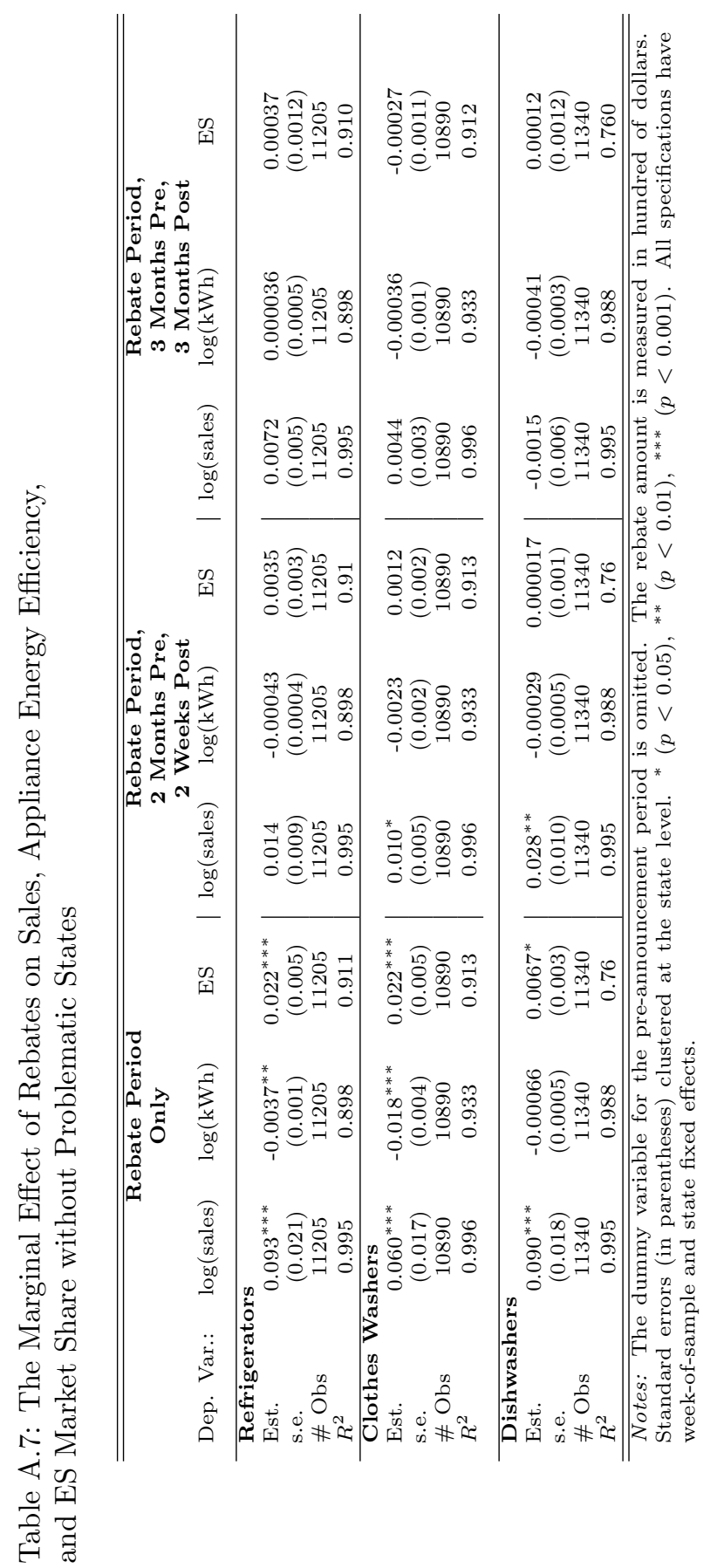


Table A.8: Impact of Program Characteristics on Appliance Energy Efficiency

\begin{tabular}{|c|c|c|c|}
\hline \multicolumn{4}{|c|}{ Dependent Variable: Percentage Energy Savings in Each State } \\
\hline & Refrigerators & Clothes Washers & Dishwashers \\
\hline Rebate Amount (\$) & $\begin{array}{l}-0.0037 \\
(0.0019)\end{array}$ & $\begin{array}{c}0.024^{* * *} \\
(0.0041)\end{array}$ & $\begin{array}{c}0.0010^{*} \\
(0.00038)\end{array}$ \\
\hline Duration (weeks) & $\begin{array}{c}0.0020 \\
(0.0015)\end{array}$ & $\begin{array}{l}-0.0039 \\
(0.0042)\end{array}$ & $\begin{array}{c}0.00025 \\
(0.00028)\end{array}$ \\
\hline Advalorem $=1$ & $\begin{array}{c}1.60 \\
(0.84)\end{array}$ & $\begin{array}{l}-2.74 \\
(2.03)\end{array}$ & $\begin{array}{c}-0.36^{*} \\
(0.13)\end{array}$ \\
\hline Online $=1$ & $\begin{array}{c}-0.036 \\
(0.55)\end{array}$ & $\begin{array}{c}1.16 \\
(1.20)\end{array}$ & $\begin{array}{l}-0.021 \\
(0.083)\end{array}$ \\
\hline Reservation System $=1$ & $\begin{array}{c}-0.21 \\
(0.52)\end{array}$ & $\begin{array}{c}-1.18 \\
(1.19)\end{array}$ & $\begin{array}{c}0.050 \\
(0.081)\end{array}$ \\
\hline Recycling Requirement $=1$ & $\begin{array}{l}-0.30 \\
(0.57)\end{array}$ & $\begin{array}{l}0.053 \\
(1.36)\end{array}$ & $\begin{array}{c}0.24^{*} \\
(0.091)\end{array}$ \\
\hline Recycling Incentive $=1$ & $\begin{array}{c}0.56 \\
(0.76)\end{array}$ & $\begin{array}{c}-0.082 \\
(1.76)\end{array}$ & $\begin{array}{l}0.010 \\
(0.11)\end{array}$ \\
\hline Eligibility Criteria $=2$ & $\begin{array}{c}1.34 \\
(0.95)\end{array}$ & $\begin{array}{c}-1.81 \\
(3.73)\end{array}$ & $\begin{array}{c}0.41 \\
(0.22)\end{array}$ \\
\hline Eligibility Criteria $=3$ & $\begin{array}{c}1.32 \\
(1.20)\end{array}$ & $\begin{array}{l}-1.37 \\
(3.94)\end{array}$ & $\begin{array}{c}0.41 \\
(0.23)\end{array}$ \\
\hline Eligibility Criteria $=4$ & $\begin{array}{c}0.64 \\
(1.45)\end{array}$ & $\begin{array}{l}-1.69 \\
(3.98)\end{array}$ & $\begin{array}{l}0.55^{*} \\
(0.24)\end{array}$ \\
\hline $\begin{array}{l}\# \text { Obs. } \\
R^{2}\end{array}$ & $\begin{array}{c}42 \\
0.332 \\
\end{array}$ & $\begin{array}{c}42 \\
0.611 \\
\end{array}$ & $\begin{array}{c}36 \\
0.621 \\
\end{array}$ \\
\hline
\end{tabular}

Notes: The dependent variable is the average energy savings in each state measured in percentage. The rebate amount is measured in hundred of dollars. A positive estimate means that a "feature" increases savings. For instance, increasing the rebate amount for clothes washers from $\$ 0$ to $\$ 100$ increases savings by $2.4 \%$. The savings were estimated over the rebate period, two months before the start of the rebate period, and two Wks. Post the end of the rebate period. The dummy "advalorem" takes the value one when ad valorem rebates are offered. The dummy "online" takes the value one if rebates could be claimed online. The dummy "reservation system" is zero if consumers had to buy then apply, and takes the value one if reservations were allowed. The eligibility criteria are coded as follows: (1) ES (omitted), (2) ES baseline with marginal rebate increases for higher efficiency, (3) more efficient than ES, and (4) more efficient than ES baseline with marginal rebate increases for higher efficiency. Standard errors in parentheses. ${ }^{*}(p<0.05),{ }^{* *}(p<0.01),{ }^{* * *}(p<0.001)$ 


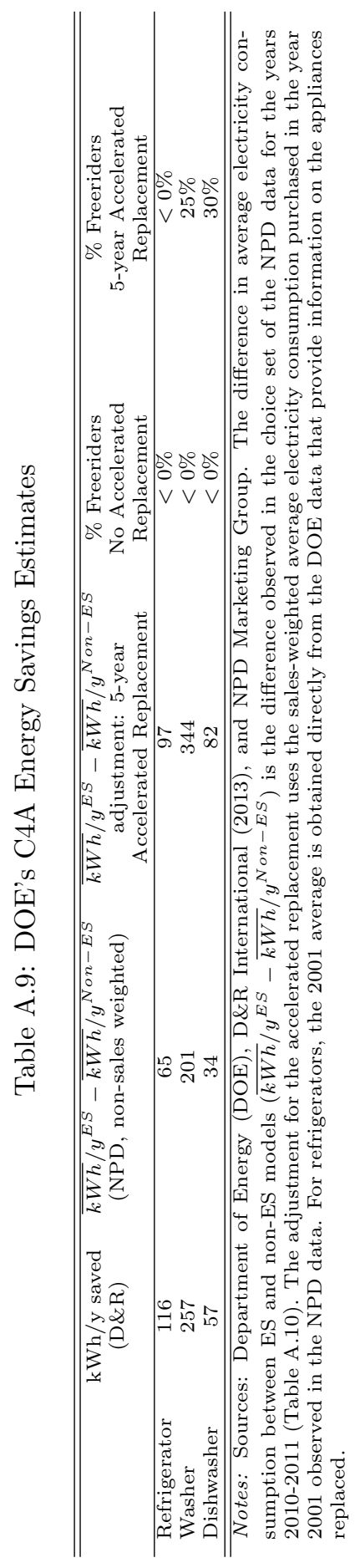




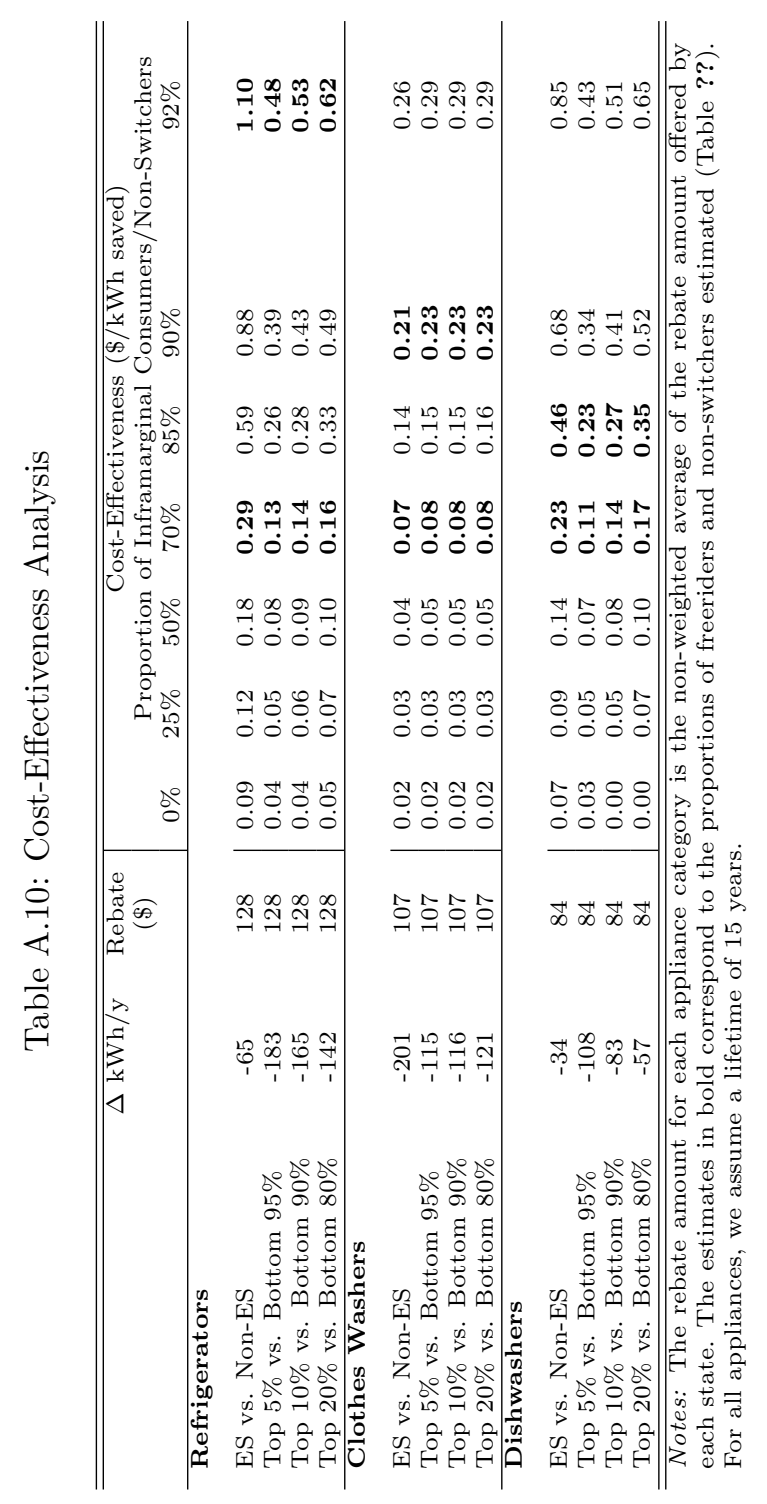




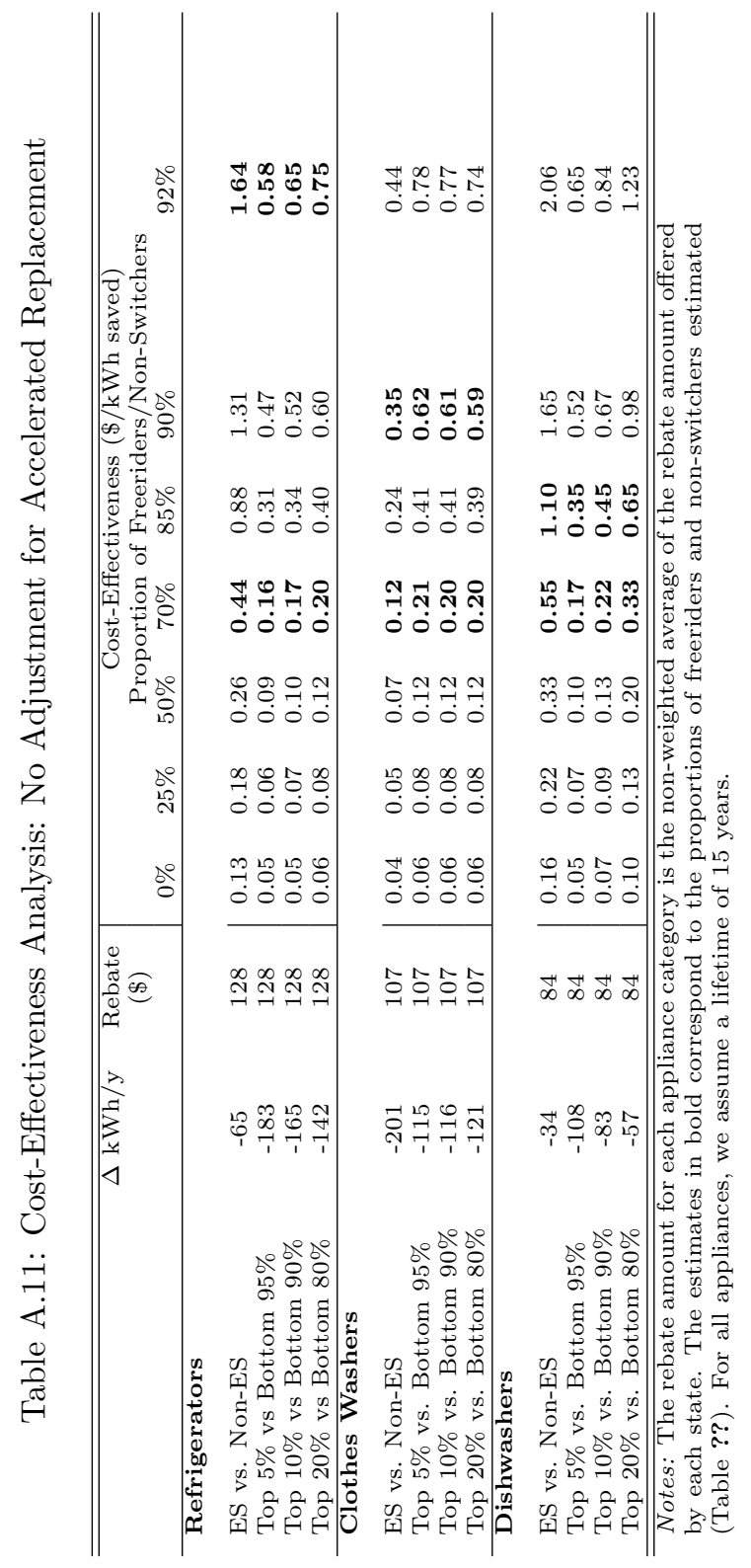

